\title{
The incidence of regression after the non- surgical treatment of symptomatic lumbar disc herniation: a systematic review and meta-analysis
}

Yi Wang ${ }^{1 *} \mathbb{D}$, Guogang Dai ${ }^{1}$, Ling Jiang ${ }^{2}$ and Shichuan Liao ${ }^{1}$

\begin{abstract}
Background: Although the regression of symptomatic lumbar disc herniation (SLDH) has been widely reported, little data exist regarding the generalized incidence of regression (IR). We aimed to review the varying IRs and to synthesize the pooled IR of non-surgically-treated SLDH.

Methods: Four electronic databases were searched for relevant studies pertaining to the regression of SLDH after non-surgical treatment and for potential studies that may have reported morphological changes in lumbar disc herniation in the follow-up results of SLDH patients treated non-surgically. The main outcome was the regression of $\mathrm{SLDH}$. A random effects model was used to determine the pooled IR of SLDH.

Results: We identified 13,672 articles, 38 of which were eligible for analysis. Our analysis included 2219 nonsurgically treated SLDH patients, 1425 of whom presented regression. The pooled IR was $63 \%$ (95\% Cl 0.49-0.77). In subgroup analyses, studies that quantitatively measured the regression of SLDH yielded statistically higher pooled IRs than those that used qualitative methods. The pooled IRs gradually increased in randomized controlled trials and prospective and retrospective studies. The pooled IR varied from 62 to $66 \%$ after the sequential omission of any single study. Meta-regression showed that study types, herniation levels and regression measurements caused heterogeneity.

Conclusions: We report an overall IR of 63\% among non-surgically treated SLDH patients, thus providing clinical decision makers with quantitative evidence of IR. Based on our systematic review, we suggest a follow-up timeline with time points 4 and 10.5 months after onset when deciding whether to perform surgery for SLDH.
\end{abstract}

Keywords: Lumbar disc herniation, Non-surgical treatment, Incidence of regression

\footnotetext{
* Correspondence: yiwang1984@hotmail.com

${ }^{1}$ Cervicodynia/Omalgia/Lumbago/Sciatica Department 2, Sichuan Provincial

Orthopedics Hospital, 132 West First Section First Ring Road, Chengdu

610041, Sichuan Province, China

Full list of author information is available at the end of the article
}

(c) The Author(s). 2020 Open Access This article is licensed under a Creative Commons Attribution 4.0 International License, which permits use, sharing, adaptation, distribution and reproduction in any medium or format, as long as you give appropriate credit to the original author(s) and the source, provide a link to the Creative Commons licence, and indicate if changes were made. The images or other third party material in this article are included in the article's Creative Commons licence, unless indicated otherwise in a credit line to the material. If material is not included in the article's Creative Commons licence and your intended use is not permitted by statutory regulation or exceeds the permitted use, you will need to obtain permission directly from the copyright holder. To view a copy of this licence, visit http://creativecommons.org/licenses/by/4.0/. The Creative Commons Public Domain Dedication waiver (http://creativecommons.org/publicdomain/zero/1.0/) applies to the data made available in this article, unless otherwise stated in a credit line to the data. 


\section{Background}

Symptomatic lumbar disc herniation (SLDH) can be treated non-surgically or surgically. Non-surgical treatment was shown to be effective for SLDH long ago [1], although surgery results in more rapid and effective short-term alleviation of symptoms than non-surgical treatment $[2,3]$. However, the long-term effects of the two have not been consistently reported [2-4], and there is a risk of complications with surgery [5]. Thus, in many cases, there is not a clear correct decision regarding the use of surgical or non-surgical treatments for SLDH [6].

Since the first case of regression after the non-surgical treatment of SLDH was reported in 1984 [7], the phenomenon of SLDH regression has been widely reported [8-46], with the incidence of regression (IR) varying from study to study. Reports on the correlation between the regression of SLDH and clinical outcomes have been contradictory: an early study observed a connection between morphological changes in SLDH and clinical outcomes [41], while later studies found that the regression of SLDH does not correspond with the resolution of symptoms $[9,47]$. However, we cannot ignore the physical decompression that occurs during regression in the acute context of SLDH, and the probable regression of SLDH still needs to be considered in clinical practice, according to the guidelines of the North American Spine Society [48]. Understanding the IR of SLDH is clearly of clinical importance. However, scant generalized data regarding the IR are currently available to serve as a reference. When making clinical decisions regarding SLDH, practitioners and patients have little high-level evidence regarding IR to which they can refer.

We therefore performed a systematic review and meta-analysis to provide a comprehensive examination of the IR of SLDH in patients who were treated nonsurgically.

\section{Methods}

This systematic review and meta-analysis is reported in compliance with the Preferred Reporting Items for Systematic Reviews and Meta-Analyses (PRISMA) statement [49]. We did not publish a prior protocol for this systematic review and meta-analysis.

\section{Search strategy}

For this systematic review and meta-analysis, we searched PubMed, Embase, the Cochrane Central Register of Controlled Trials, and the Web of Science (from inception to September 16, 2019). Search terms included those related to intervertebral disc herniation, regression, comparison, outcome, follow-up, image, and their variants. To avoid missing articles without information about the language in the database records, there was no language limitation in the literature search. A sample search strategy can be found in an additional file. We included studies identified from the references of included articles and other review articles on the topic. Two reviewers performed the searches. Disagreements were resolved by discussion with a third reviewer.

\section{Eligibility and exclusion criteria}

Relevant articles pertaining to the phenomenon of the regression of SLDH after non-surgical treatment and potential studies that may have reported morphological changes in lumbar disc herniation (LDH) among the follow-up results for non-surgically-treated SLDH patients were included, with the publication language restricted to English. Randomized controlled trials (RCTs) and nonrandomized studies were eligible for inclusion. The following studies were excluded: 1 . Studies that only reported the follow-up results of surgery, including percutaneous endoscopic transforaminal discectomy, microendoscopic discectomy, microdiscectomy, fenestration discectomy, open discectomy, lumbar laminectomy, lumbar interbody fusion and radiofrequency ablation; 2 . Studies on cervical discs; 3. Studies that did not report the morphological changes in SLDH; 4. Studies that did not report the number of patients exhibiting regression; 5. Studies on only intradiscal injections, including oxygen-ozone therapy, plasma injection and collagenase chemonucleolysis; 6. Studies on asymptomatic LDH; 7. Studies with less than 10 patients at follow-up; 8. Animal studies; 9. Reviews; and 10. Studies that did not report specific non-surgical treatment.

\section{Quality assessment}

The quality of the nonrandomized studies was assessed based on the Methodological Index for Nonrandomized Studies (MINORS) [50]. There is no consensus on when the regression of $\mathrm{LDH}$ occurs; thus, item six of the MINORS (follow-up period appropriate to the aim of the study) was not applicable, and the highest total score was 14 (high quality: 10-14; moderate quality: five-nine; and low quality: zero-four). The risk of bias of RCTs was evaluated using a tool from the Cochrane Collaboration [51]. Considering the nature of RCTs of the non-surgical treatment of SLDH, performance bias was generally not a particular concern and had a minor impact on the study quality. Thus, we considered all the included RCTs to have a low risk of performance bias. RCTs were categorized as having a high, low, or unclear risk according to the following criteria: high risk, any item presented a high risk; low risk, no more than 2 items presented an unclear risk; and unclear risk, more than 2 items presented an unclear risk. Two reviewers independently assessed the quality of the included studies and extracted the data. Disagreements were resolved by consensus with a third reviewer. 


\section{Data extraction and analysis}

Relevant data were extracted using a standardized form that included the publication year, country, study type, study quality or risk of bias, LDH level, regression measurement, imaging method, patient count, total number of SLDH patients at follow-up and number of patients with SLDH regression, as well as age, symptom duration, nerve symptoms, whether regression was defined and follow-up duration. The primary outcome was the IR of SLDH after nonsurgical treatment. The IR was estimated based on the total number of SLDH patients at follow-up and the number of patients that experienced regression. For studies that recorded the number of patients according to the regressed proportion or size interval but did not define the interval of non-regression or the number of patients without regression, we regarded the lowest interval as the no-regression range, and the number of patients outside of this interval was considered the number of patients with regression. For studies in which more than two imaging examinations were performed, we used the author's final count, and if no final count was provided, the latest imaging examinations with enough information were compared to the baseline examinations. For studies reporting the same cohort or trial, only the latest study was included. For studies with overlapping data, we selected the study with the highest number of patients at the last follow-up. Herniations after baseline were not counted. For RCTs, we calculated the total number of occurrences in the two groups.

The $\mathrm{I}^{2}$ statistic was employed to evaluate the heterogeneity of pooled data, and the DerSimonian and Laird random effects model was used to pool the IRs with corresponding 95\% confidence intervals (CIs). Incidences from studies with zero events were treated by adding 0.5 cases to both the numerator (number of patients with regression) and denominator (total number of SLDH patients), consistent with recommended practices [52]. Subgroup analysis was performed by stratifying the studies according to the time period, region, study type, LDH level, regression measurement, imaging method and method used to determine the patient count. Potential sources of heterogeneity were explored by meta-regression with a $p$ value less than 0.1. Sensitivity analysis was performed by including only high-quality non-randomized studies and low-risk RCTs and by sequentially excluding each study. Publication bias was assessed using Egger's test and was visualized with a funnel plot. All statistical analyses were performed using the Meta and metafor packages in R (V3.6.1) [53].

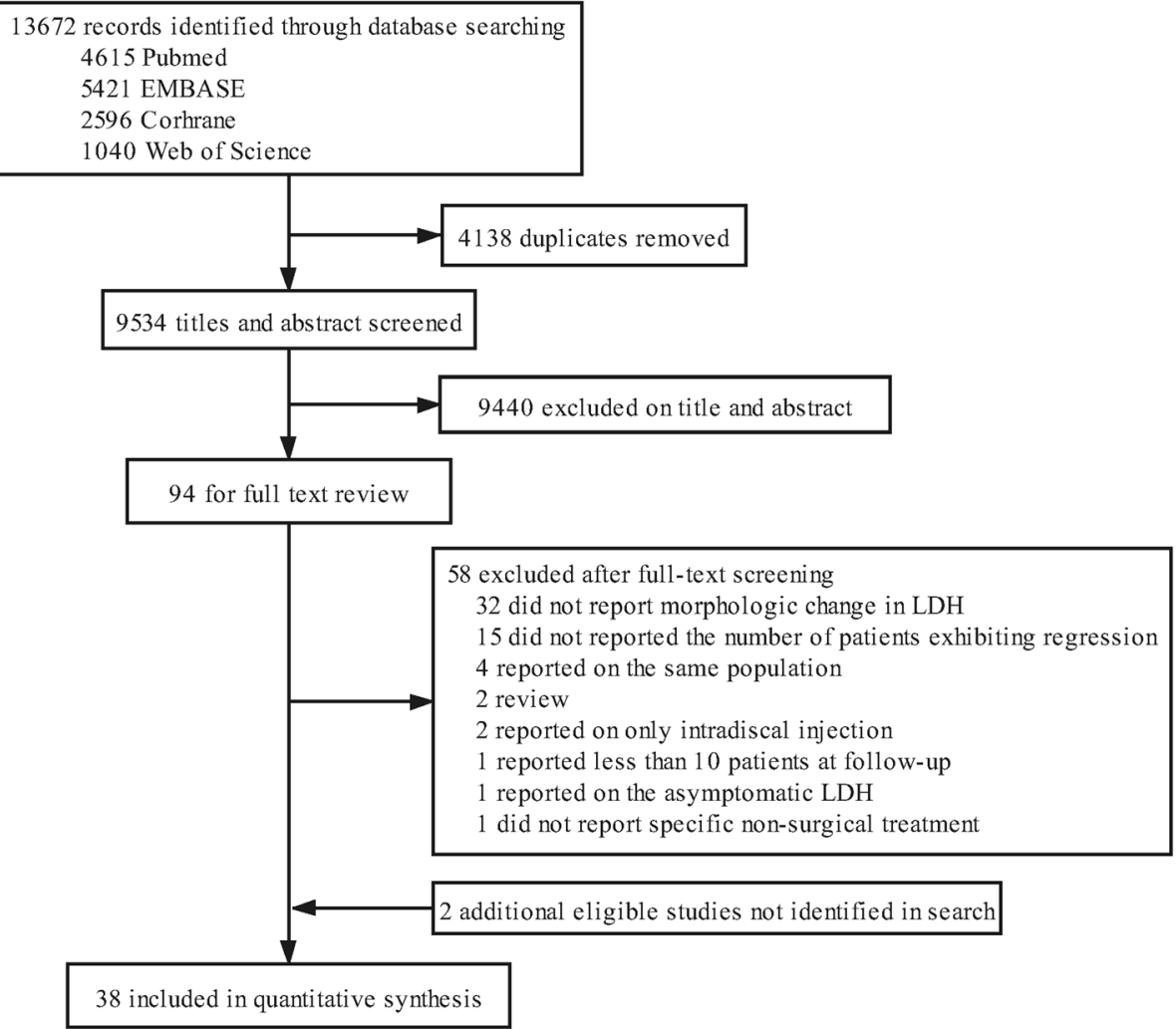

Fig. 1 Study selection 
Table 1 Characteristics of the included studies

\begin{tabular}{|c|c|c|c|c|c|c|c|c|c|c|}
\hline \multirow[t]{2}{*}{ Author } & \multirow[t]{2}{*}{ Year } & \multirow[t]{2}{*}{ Country } & \multirow[t]{2}{*}{ Study type } & \multirow[t]{2}{*}{ Quality $^{a}$} & \multirow[t]{2}{*}{ LDH Level $^{b}$} & \multirow[t]{2}{*}{ Measurement } & \multirow[t]{2}{*}{$\begin{array}{l}\text { Imaging } \\
\text { method }\end{array}$} & \multirow[t]{2}{*}{ Counting $^{c}$} & \multicolumn{2}{|l|}{$\begin{array}{l}\text { Number of } \\
\text { patients }\end{array}$} \\
\hline & & & & & & & & & Regression & Total \\
\hline El Barzouhi et al. [9] & 2013 & Netherlands & $\mathrm{RCT}$ & Low risk & single & Qualitative & MRI & $A$ & 88 & 95 \\
\hline Santilli et al. [10] & 2006 & Italy & RCT & Low risk & single/multiple & Qualitative & MRI & A & 0 & 102 \\
\hline Fan et al. [11] & 2015 & China & RCT & $\begin{array}{l}\text { Unclear } \\
\text { risk }\end{array}$ & Unknow & Qualitative & MRI & A & 0 & 158 \\
\hline Ahn et al. [12] & 2002 & Korea & Prospective & 11 & single & Qualitative & MRI & B & 13 & 17 \\
\hline Maigne et al. [13] & 1992 & France & Prospective & 10 & single & Qualitative & CT & $\mathrm{B}$ & 39 & 48 \\
\hline Benson et al. [14] & 2010 & UK & Prospective & 12 & single & Quantitative & MRI & B & 28 & 32 \\
\hline Komori et al. [15] & 1998 & Japan & Retrospective & 12 & single & Qualitative & MRI & A & 19 & 22 \\
\hline Modic et al. [16] & 1995 & USA & Prospective & 12 & single/multiple & Qualitative & MRI & B & 4 & 16 \\
\hline Kamanli et al. [17] & 2010 & Turkey & Prospective & 8 & Unknown & Qualitative & MRI & A & 5 & 26 \\
\hline Autio et al. [18] & 2006 & Finland & Prospective & 12 & single & Quantitative & MRI & A & 51 & 55 \\
\hline Gallucci et al. [19] & 1995 & Italy & Prospective & 10 & Unknown & Qualitative & MRI & B & 11 & 15 \\
\hline Ozturk et al. [20] & 2006 & Turkey & RCT & Low risk & single/multiple & Quantitative & $\mathrm{CT}$ & A & 19 & 46 \\
\hline Ahn et al. [21] & 2000 & Korea & Prospective & 12 & single & Quantitative & MRI & A & 25 & 36 \\
\hline Ilkko et al. [22] & 1993 & Finland & Unknown & 7 & single/multiple & Qualitative & CT & A & 15 & 18 \\
\hline Delauche-Cavallier et al. [23] & 1992 & France & Prospective & 9 & single & Qualitative & CT & $A$ & 14 & 21 \\
\hline Buttermann et al. [24] & 2002 & USA & Prospective & 10 & single & Quantitative & MRI & A & 52 & 58 \\
\hline Bozzao et al. [25] & 1992 & Italy & Prospective & 10 & Unknow & Qualitative & MRI & A & 41 & 65 \\
\hline Broetz et al. [26] & 2008 & Germany & Prospective & 9 & Unknow & Qualitative & MRI & A & 0 & 10 \\
\hline Jensen et al. [27] & 2006 & Denmark & Prospective & 10 & Unknow & Qualitative & MRI & A & 65 & 139 \\
\hline Henmi et al. [28] & 2002 & Japan & Unknown & 11 & single & Quantitative & MRI & A & 4 & 10 \\
\hline Takada et al. [29] & 2001 & Japan & Prospective & 9 & single & Qualitative & MRI & A & 37 & 42 \\
\hline Cribb et al. [30] & 2007 & England & Unknown & 7 & single & Quantitative & MRI & A & 14 & 15 \\
\hline Ellenberg et al. [31] & 1993 & USA & Prospective & 9 & single/multiple & Qualitative & $C T$ & A & 11 & 14 \\
\hline Demirel et al. [32] & 2017 & Turkey & RCT & Low risk & single/multiple & Quantitative & MRI & A & 18 & 20 \\
\hline Hong et al. [33] & 2016 & Korea & Retrospective & 10 & single & Quantitative & MRI & A & 24 & 28 \\
\hline Matsubara et al. [34] & 1995 & Japan & Unknown & 9 & single & Qualitative & MRI & B & 20 & 32 \\
\hline Yukawa et al. [35] & 1996 & Japan & Unknown & 11 & single & Quantitative & MRI & A & 17 & 30 \\
\hline Fagerlund et al. [36] & 1990 & Sweden & Prospective & 12 & single & Qualitative & $C T$ & B & 22 & 30 \\
\hline Kesikburun et al. [37] & 2019 & Turkey & Prospective & 12 & single & Quantitative & MRI & $A$ & 36 & 40 \\
\hline Teplick et al. [38] & 1985 & USA & Unknown & 7 & Unknown & Qualitative & $C T$ & A & 11 & 55 \\
\hline Shan et al. [39] & 2014 & China & Retrospective & 12 & single & Quantitative & $\mathrm{MRI}$ & $A$ & 24 & 30 \\
\hline Shin et al. [40] & 2017 & Korea & Prospective & 8 & Unknown & Qualitative & MRI & A & 42 & 73 \\
\hline Komori et al. [41] & 1996 & Japan & Retrospective & 10 & single & Qualitative & MRI & A & 49 & 77 \\
\hline Saal et al. [42] & 1990 & USA & Unknown & 8 & Unknown & Qualitative & $\mathrm{CT} / \mathrm{MRI}$ & B & 9 & 11 \\
\hline Bush et al. [43] & 1992 & UK & Prospective & 10 & single/multiple & Qualitative & $C T$ & A & 71 & 111 \\
\hline Iwabuchi et al. [44] & 2010 & Japan & Prospective & 10 & single & Qualitative & MRI & A & 21 & 34 \\
\hline Yu et al. [45] & 2014 & China & Unknown & 10 & single & Qualitative & MRI & A & 20 & 83 \\
\hline Lee et al. [46] & 2017 & Korea & Retrospective & 10 & single & Quantitative & $\mathrm{MRI}$ & A & 486 & 505 \\
\hline
\end{tabular}

${ }^{a}$ Quality of non-randomized studies was assessed following the MINORS; the risk of bias of RCTs was evaluated using a tool from the Cochrane Collaboration ${ }^{b}$ Some studies included only single-level SLDH patients and some studies included both single- and multiple-level SLDH patients

cCounting. A. The number of patients with regression was reported and was extracted from the publication. B: For studies that recorded the number of patients by the regression proportion or size interval but did not define the interval of non-regression or report the number of patients without regression, we regarded the lowest interval as the no regression range, and the number of patients outside of this interval was considered the number of patients with regression 


\section{Results}

\section{Study selection and characteristics}

Our initial search yielded 13,672 articles, and two were hand-selected from reference lists. A total of 38 articles were included in the final meta-analysis (Fig. 1). The non-surgical treatment used in these studies included bed rest, lumbar support, traction, spinal manipulation, physical therapy, exercise, oral steroids, analgesics, nonsteroidal anti-inflammatory agents, epidural block, caudal epidural injections, traditional Chinese medicine and alternative medicine. These articles included 5 RCTs and 33 nonrandomized studies. The studies were from

Table 2 Other characteristics of the included studies

\begin{tabular}{|c|c|c|c|c|c|c|}
\hline Author & Year & Age & Duration of symptom & Nerve symptom & Regression defined & Follow-up \\
\hline El Barzouhi et al. [9] & 2013 & $18-65$ & $6-12 \mathrm{~W}$ & Yes & Yes & $1 Y$ \\
\hline Santilli et al. [10] & 2006 & $18-65$ & Less than $10 \mathrm{D}$ & Yes & Yes & $45 D$ \\
\hline Fan et al. [11] & 2015 & Unknown & Unknown & Yes & No & $20 D$ \\
\hline Ahn et al. [12] & 2002 & 19-73 (42.7) & 1-10 W(median 4.5 W) & Some & Yes & 3-11 M(11.9 M) \\
\hline Maigne et al. [13] & 1992 & $26-75(45.2)$ & Unknown & Yes & Yes & $1-48 M$ \\
\hline Benson et al. [14] & 2010 & $25-62(40.4)$ & More than $6 \mathrm{~W}$ & Yes & Yes & 3-42 M(13.2 M) \\
\hline Komori et al. [15] & 1998 & 20-75 (41) & 2-359D(54D) & Yes & Yes & 27-856D(151D) \\
\hline Modic et al. [16] & 1995 & 22-75 (49.2) & Less than $2 \mathrm{~W}$ & Yes & Yes & $6 \mathrm{~W}-6 \mathrm{M}$ \\
\hline Kamanli et al. [17] & 2010 & (37) & Unknown & Unknown & No & $4-6 W$ \\
\hline Autio et al. [18] & 2006 & 19-78 & $3-28 \mathrm{~W}$ & Yes & Yes & $12 \mathrm{M}$ \\
\hline Gallucci et al. [19] & 1995 & $27-62(37)$ & Unknown & Some & Yes & $6 \mathrm{M}$ \\
\hline Ozturk et al. [20] & 2006 & $16-70$ & Less than $6 \mathrm{M}$ & Some & Yes & $21 D$ \\
\hline Ahn et al. [21] & 2000 & 17-74 (39) & $1-28 \mathrm{M}$ & Yes & Yes & 3-27 M(8.5 M) \\
\hline Ilkko et al. [22] & 1993 & $35-74(53)$ & Unknown & Some & Yes & $4.3-6.1 Y(5.2 Y)$ \\
\hline Delauche-Cavallier et al. [23] & 1992 & 20-64 (43) & 15D-6 M(2 M) & Yes & Yes & 6-27 M(12.9 M) \\
\hline Buttermann et al. [24] & 2002 & $18-70$ & Unknown & Yes & Yes & $18 \pm 10 \& 19 \pm 9 \mathrm{M}$ \\
\hline Bozzao et al. [25] & 1992 & $23-65(52)$ & $1 \mathrm{M}-1 \mathrm{Y}$ & Some & Yes & 6-15 M(11 M) \\
\hline Broetz et al. [26] & 2008 & $18-65$ & 5D-2Y(median $5 \mathrm{~W}$ ) & Yes & No & $3-7 D(5 D)$ \\
\hline Jensen et al. [27] & 2006 & $18-65(45)$ & $1-3 M$ & Yes & Yes & $12 \mathrm{M}$ \\
\hline Henmi et al. [28] & 2002 & $20-50$ & $1-200 D$ & Yes & Yes & $6-12 M$ \\
\hline Takada et al. [29] & 2001 & $16-64(42)$ & $1-14 W$ & Yes & Yes & 3-24 M(10.3 M) \\
\hline Cribb et al. [30] & 2007 & $24-73(45)$ & Unknown & Yes & No & 5-56 M(24 M) \\
\hline Ellenberg et al. [31] & 1993 & $28-67(42)$ & Unknown & Yes & Yes & 6-18 M(9.8 M) \\
\hline Demirel et al. [32] & 2017 & 50.7 & Unknown & Unknown & Yes & $3 \mathrm{M}$ \\
\hline Hong et al. [33] & 2016 & 26-78 (50.2) & Unknown & Unknown & Yes & 2-31 M(8.8 M) \\
\hline Matsubara et al. [34] & 1995 & $16-52(36)$ & Unknown & Yes & Yes & 3-18 M(9.7 M) \\
\hline Yukawa et al. [35] & 1996 & 14-69 (39) & Unknown & Yes & Yes & 24-42 M(30 M) \\
\hline Fagerlund et al. [36] & 1990 & $14-49(35)$ & $6 \pm 3 M$ & Unknown & Yes & $24 \mathrm{M}$ \\
\hline Kesikburun et al. [37] & 2019 & $39.7-71.5(54.4)$ & 4.7-7.4 M(6 M) & No & Yes & 12-19 M(17 M) \\
\hline Teplick et al. [38] & 1985 & Unknown & Unknown & Unknown & No & $3 M-5 Y$ \\
\hline Shan et al. [39] & 2014 & $20-66(40)$ & $2 \mathrm{~W}-6 \mathrm{M}$ & Yes & Yes & $6 \mathrm{M}$ \\
\hline Shin et al. [40] & 2017 & $(35.8)$ & $(2.7 \mathrm{M})$ & Yes & Yes & $3 Y$ \\
\hline Komori et al. [41] & 1996 & $18-86(41)$ & $0.1-8.6 \mathrm{M}(1.8 \mathrm{M})$ & Yes & Yes & $62-1208 D(262 D)$ \\
\hline Saal et al. [42] & 1990 & Unknown & Unknown & Yes & Yes & 8-77 M(25) \\
\hline Bush et al. [43] & 1992 & $17-72(41)$ & 1-72 M(4.2 M) & Yes & Yes & $1 Y$ \\
\hline Iwabuchi et al. [44] & 2010 & -52 & Unknown & Yes & Yes & (4.1 M) \\
\hline Yu et al. [45] & 2014 & $16-60(38.7)$ & 3D-10Y(16.5 M) & Yes & Yes & $2-24 M$ \\
\hline Lee et al. [46] & 2017 & $39.08 \pm 10.19$ & Unknown & Yes & Yes & $341.38 \pm 306.83 D$ \\
\hline
\end{tabular}

Average values were presented in parentheses and " \pm "is connected to Mean and SD if available. $D$ Day, M Month, $Y$ Year 
Asia, Europe and North America and were from a total of 13 countries. Japan contributed seven studies; Korea and the USA each contributed five; Turkey contributed four; China, the UK and Italy each contributed three; France and Finland each contributed two; and Denmark, Germany, the Netherlands and Sweden each contributed one. The imaging examinations used were magnetic resonance imaging (MRI) in 29 studies and computed tomography (CT) in eight studies, and one study used CT at baseline and MRI at follow-up. The characteristics of the included studies are summarized in Table 1. These studies reported patient age (14-78), symptom duration (one day-ten years) and follow-up time (20 days - 6.1 years) in different formats (Table 2). A total of 16 studies did not report symptom duration, five studies did not report whether nerve symptoms were experienced by all patients or by a subset of patients, and five studies did not describe or define regression (Table 2).

\section{Quality assessment}

Of the 5 included RCTs, 4 showed a low risk of bias, and 1 showed an unclear risk of bias. Of the 33 included non-randomized studies, 22 were of high quality, and 11 were of moderate quality (Table 1).

\section{Incidence synthesis and data analysis}

The pooled analysis for IR after the nonsurgical treatment of SLDH included 2219 patients, 1425 of whom presented regression. The pooled IR in our study was 63\% (95\% CI 0.49-0.77), with significant heterogeneity among the studies $\left(\mathrm{I}^{2}=97.7 \%, p<0.001\right.$; Fig. 2$)$.

Subgroup analyses (Table 3) showed that studies that quantitatively measured the regression of SLDH yielded statistically higher $(p=0.02)$ pooled IRs $(81,95 \% \mathrm{CI}$ 0.69-0.91) than those that adopted qualitative methods (54, 95\% CI 0.37-0.70). We repeated subgroup analyses based on the time period of the study and did not identify any secular trends in the IR of non-surgically treated

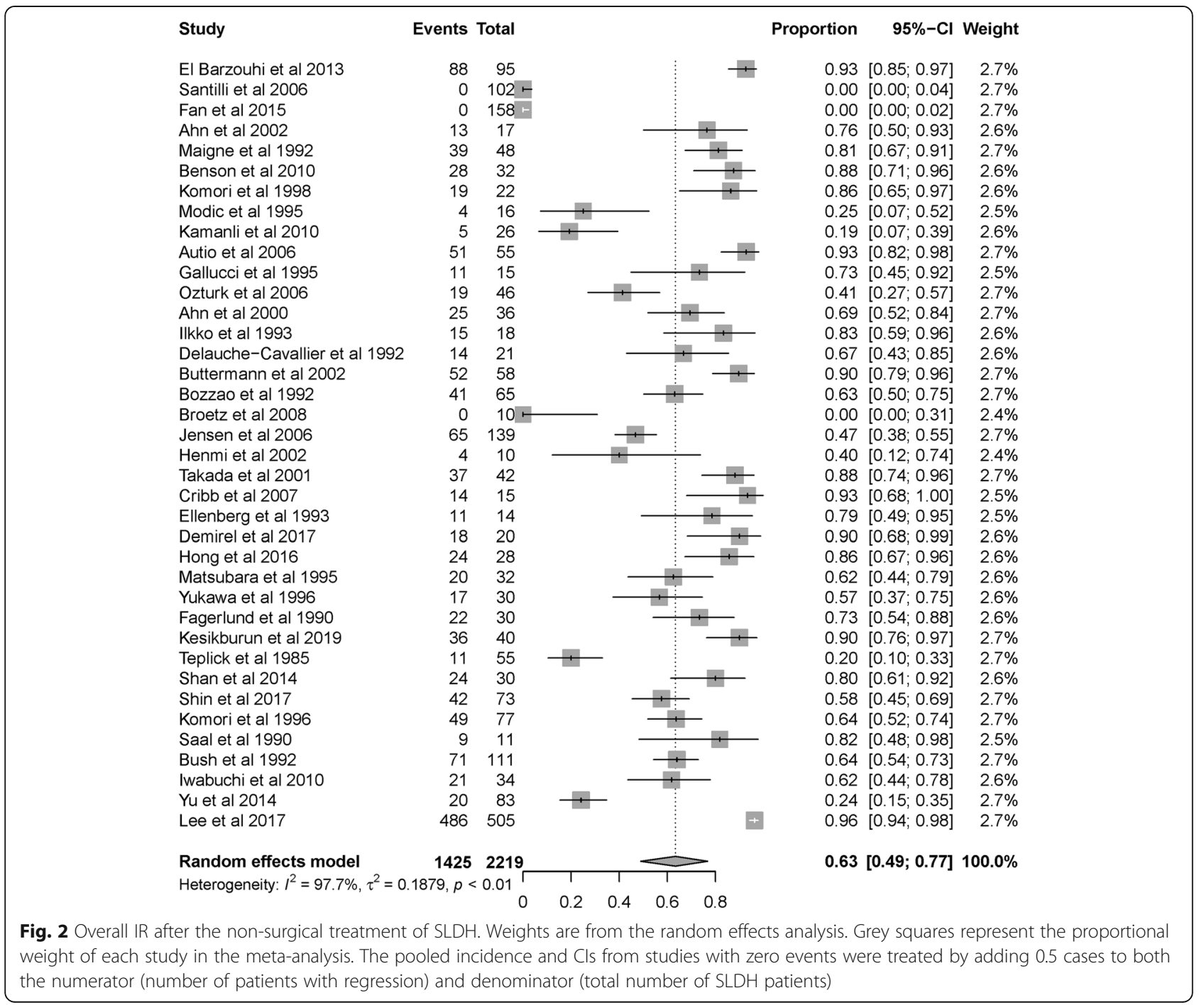


Table 3 Subgroup analyses of the regression measurement, time period, region, study type, LDH level, imaging method and patient count

\begin{tabular}{|c|c|c|c|c|c|}
\hline & \multirow{2}{*}{$\begin{array}{l}\text { Included } \\
\text { studies (n) }\end{array}$} & \multicolumn{2}{|c|}{ Number of patients } & \multirow{2}{*}{$\begin{array}{l}\text { Incidence } \\
(95 \% \mathrm{Cl})\end{array}$} & \multirow{2}{*}{$\begin{array}{l}\boldsymbol{P} \\
\text { value }\end{array}$} \\
\hline & & With Regression & Total & & \\
\hline Measurement & 38 & 1425 & 2219 & $63 \%(0.49-0.77)$ & 0.01 \\
\hline Qualitative & 25 & 627 & 1314 & $54 \%(0.37-0.70)$ & \\
\hline Quantitative & 13 & 798 & 905 & $81 \%(0.69-0.91)$ & \\
\hline Time period & 38 & 1425 & 2219 & $63 \%(0.49-0.77)$ & 0.87 \\
\hline Before 2000 & 15 & 353 & 565 & $65 \%(0.55-0.75)$ & \\
\hline 2000-2009 & 11 & 280 & 530 & $57 \%(0.29-0.83)$ & \\
\hline 2010-2019 & 12 & 792 & 1124 & $66 \%(0.35-0.91)$ & \\
\hline Region & 38 & 1425 & 2219 & $63 \%(0.49-0.77)$ & 0.97 \\
\hline Asia & 19 & 879 & 1309 & $63 \%(0.40-0.83)$ & \\
\hline Europe & 14 & 459 & 756 & $65 \%(0.43-0.85)$ & \\
\hline North America & 5 & 87 & 154 & $60 \%(0.22-0.92)$ & \\
\hline Study type & $30^{\mathrm{a}}$ & 1315 & 1965 & $65 \%(0.48-0.80)$ & 0.14 \\
\hline RCT & 5 & 125 & 421 & $37 \%(0.00-0.88)$ & \\
\hline Prospective & 20 & 588 & 882 & $67 \%(0.57-0.77)$ & \\
\hline Retrospective & 5 & 602 & 662 & $84 \%(0.65-0.97)$ & \\
\hline LDH level & $29^{b}$ & 1241 & 1667 & $72 \%(0.58-0.84)$ & 0.17 \\
\hline Single & 22 & 1103 & 1340 & $78 \%(0.67-0.87)$ & \\
\hline Single/multiple & 7 & 138 & 327 & $51 \%(0.17-0 \cdot 86)$ & \\
\hline Imaging method & $37^{c}$ & 1416 & 2208 & $63 \%(0.48-0.76)$ & 0.97 \\
\hline $\mathrm{CT}$ & 8 & 202 & 343 & $63 \%(0.46-0.79)$ & \\
\hline MRI & 29 & 1214 & 1865 & $63 \%(0.45-0.79)$ & \\
\hline Counting $^{d}$ & 38 & 1425 & 2219 & $63 \%(0.49-0.77)$ & 0.33 \\
\hline A & 30 & 1279 & 2018 & $61 \%(0.44-0.77)$ & \\
\hline B & 8 & 146 & 201 & $72 \%(0.59-0.83)$ & \\
\hline
\end{tabular}

${ }^{*} P$ value is from the test for subgroup differences (random effects model)

${ }^{a}$ Eight studies did not report study type

${ }^{\mathrm{b}}$ Nine studies did not report LDH level

'One study used CT at basline and MRI at follow-up

${ }^{d}$ Counting. A. The number of patients with regression was reported and was extracted from the publication. B. For studies that recorded the number of patients by the regression proportion or size interval but did not define the interval of non-regression or report the number of patients without regression, we regarded the lowest interval as the no regression range, and the number of patients outside of this interval was considered the number of patients with regression

patients before $2000(65,95 \%$ CI $0.55-0.75)$, from 2000 to 2009 (57\%, 0.29-0.83), or from 2010 to 2019 (66\%, 0.35$0.91)$. We found no significant regional variation within Asia (63, 95\% CI 0.40-0.83), Europe (65\%, 0.43-0.85), and North America (60\%, 0.22-0.92). The pooled IR gradually increased in RCTs $(37,95 \%$ CI $0.00-0.88)$, prospective studies (67\%, 0.57-0.77), and retrospective (84\%, 0.650.97 ) studies. Studies of single-level SLDH patients (78, 95\% CI 0.67-0.87) yielded higher pooled IRs than those that included both single- and multiple-level SLDH patients $(51 \%, 0.17-0.86)$. Studies based on MRI yielded the same pooled IR $(63,95 \%$ CI $0.46-0.79)$ as those based on CT (63, 95\% CI 0.45-0.79); the IR was calculated as $82 \%$ in Saal's research [42], in which CT was used at baseline and MRI was used at follow-up. Studies that reported the number of patients without regression yielded lower pooled IRs $(61,95 \%$ CI $0.44-0.77)$ than those that did not define regression or reported the number of patients without regression (72\%, 0.59-0.83).

Meta-regression showed that study types $\left(\mathrm{R}^{2}=41.94 \% p=\right.$ $0.02)$, $\mathrm{LDH}$ levels $\left(\mathrm{R}^{2}=31.53 \%, p=0.05\right)$, and regression measurements $\left(R^{2}=41.94 \% p=0.02\right)$ contributed to the heterogeneity. There was no significant change in the pooled IR (69, $95 \%$ CI $0.54-0.82)$ or heterogeneity $\left(\mathrm{I}^{2}=97.2 \%, p<0.001\right)$ when only high-quality non-randomized studies and low-risk RCTs were included (Fig. 3). The pooled IR varied from 62 to $66 \%$ after the sequential omission of any single study.

\section{Publication bias}

Egger's test suggested that there was no publication bias $(p=0.46)$. No asymmetric patterns were seen in the funnel plot (Fig. 4). 


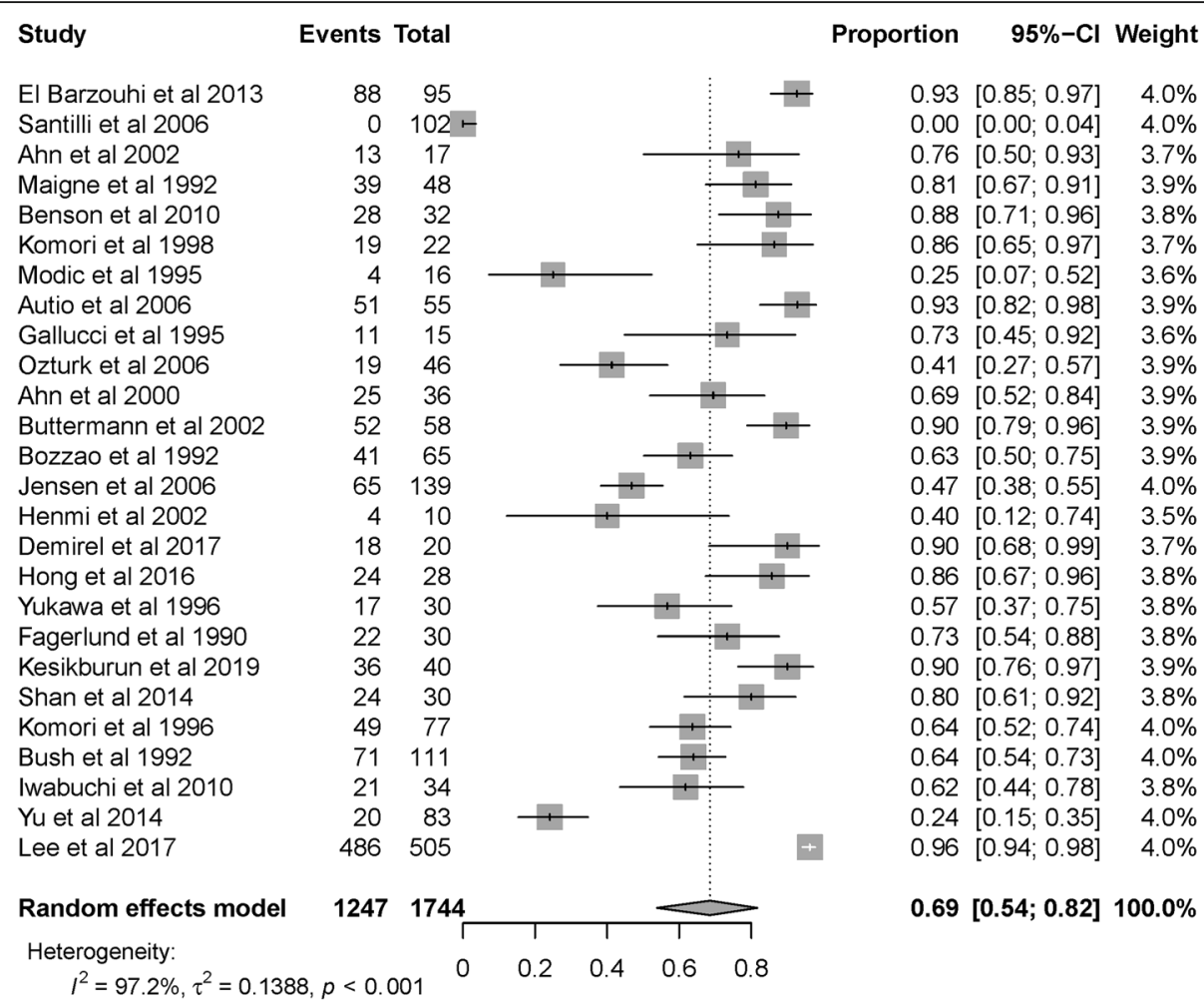

Fig. 3 Forest plot for the meta-analysis of high-quality nonrandomized studies and low-risk RCTs

\section{Discussion}

We found an IR of $63 \%$ after the non-surgical treatment of SLDH in the present systematic review and metaanalysis, with significant heterogeneity among the studies. Our pooled IR needs to be interpreted with caution.

We comprehensively searched for studies that potentially reported morphological changes in SLDH during clinical follow-up and that investigated the regression of SLDH. We conducted a wide database search, and a small number of articles were included. Because followup is a necessary step to study regression, "follow up" or "follow-up" or "outcome" or "result" was included in the search terms. The use of these search terms resulted in the retrieval of a large number of articles. However, there are so many non-surgical treatment methods for SLDH in the world that it is impossible to limit the specific non-surgical treatment methods in the literature search process. In addition, studies that compared the results of surgical and non-surgical treatment may have reported the morphological changes in herniated discs of the non-surgically treated patients, making it impossible to exclude studies on surgery. As a result, 13,672 articles were identified, more than half of which were studies on surgery for SLDH, and a small number of articles were included. Both RCTs and non-randomized studies were included in our study. The pooled IR in our study was similar to the IR of $66.66 \%$ that was reported in a previous review of 11 studies [54], and these IR values can be considered quantitative data that can inform clinical decisions regarding SLDH.

The highest IR (96\%) was documented by Lee with an average follow-up of 341 days [46], suggesting that we should seriously consider the probability of SLDH regression. Three studies reported no regression with follow-ups of 45 days [10], 20 days [11], and a median of 5 days (3-7 days) [26], suggesting that SLDH regression should not be expected to occur within one and a half months of symptom onset. The average of the IRs reported in the included studies was $63 \%$, which is the same as the pooled IR of the meta-analysis, and 7 studies reported IRs of approximately 63\%: Ahn [21] reported an IR of $69 \%$ with an average follow-up time of 8.5 months, Delauche-Cavallier [23] reported an IR of $67 \%$ with an average follow-up time of 12.5 months, Bozzao [25] reported an IR of $63 \%$ with an average follow-up time of 11 months, Matsubara [34] reported an IR of $62 \%$ with an average follow-up time of 9.7 months, Komori [41] reported an IR of $64 \%$ with an average follow-up time of 262 days, Bush [43] reported an IR of $64 \%$ with an average follow-up time of 1 year, and Iwabuchi [44] reported an IR of $62 \%$ with an average followup time of 4.1 months. According to Iwabuchi's report, which reported an IR that was consistent with the average of the IRs reported for the included studies and had 


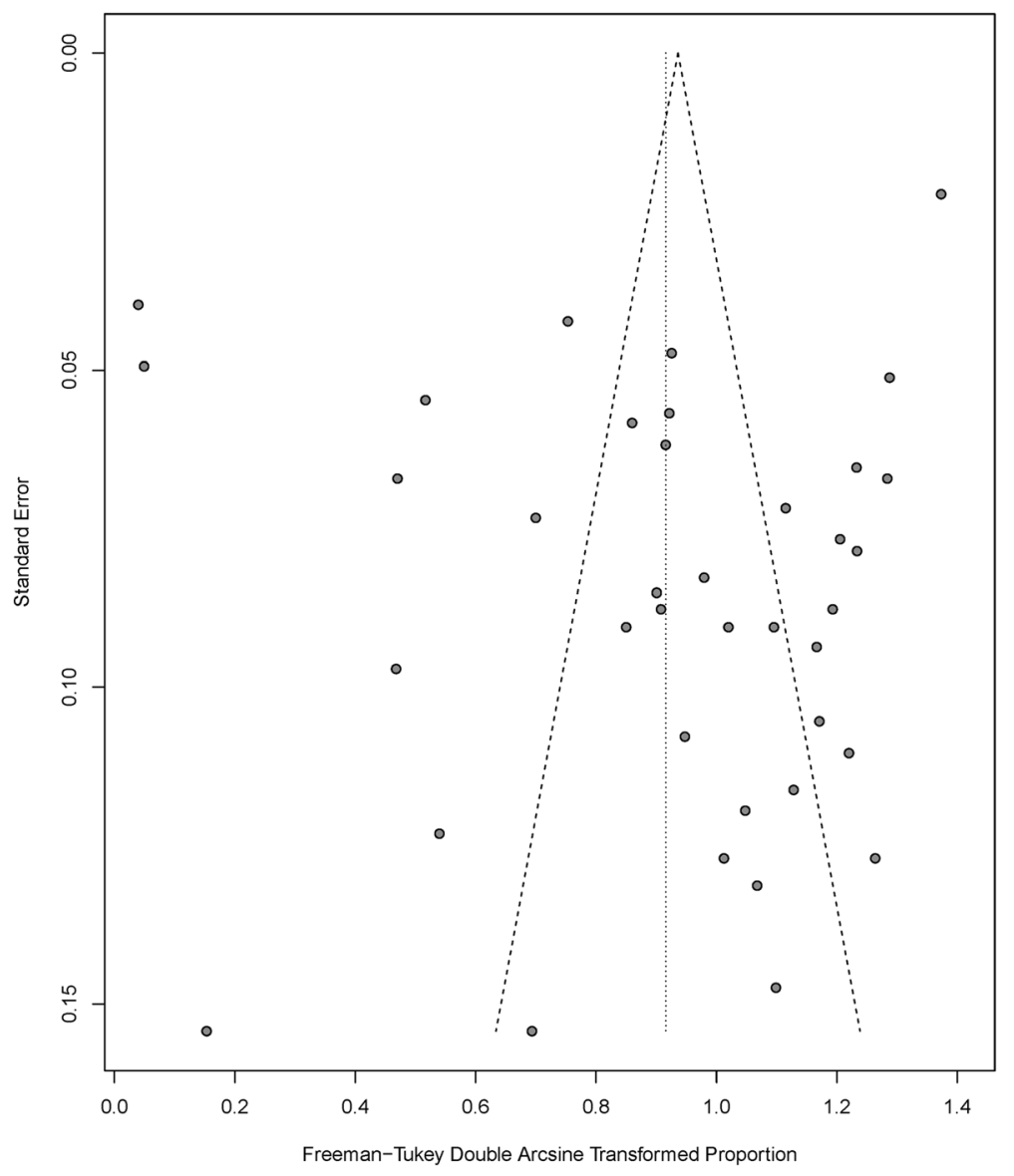

Fig. 4 Funnel plot of incidence

a follow-up time of 4.1 months [44], we suggest that 4 months after onset is an important time point for imaging. The follow-up time of the other 6 studies with IRs of approximately $63 \%$ ranged from 8.5 to 12.9 months, with an average of 10.5 months. Therefore, we suggest that 10.5 months after onset is another important time point for imaging. There were 4 studies that reported long-term follow-up, with an average duration of more than 24 months: Fagerlund [36] reported an IR of 73\% with a follow-up of 24 months, Yukawa [35] reported an IR of $57 \%$ with an average follow-up of 30 months, Shin [40] reported an IR of 58\% with a follow-up of 3 years, and Ilkko [22] reported an IR of $83 \%$ with an average follow-up of 5.2 years. The IR trend reported by these articles over time was inconsistent; some reported that IR increased over time to above the average IR, some reported that IR decreased over time to fall below the average IR, and no secular trends were identified for long-term follow-up.

We did not classify SLDH during the data synthesis, as most of the studies included in our meta-analysis did not include classifications; this is in contrast to another review that calculated IR based on 9 articles reporting that sequestration, extrusion, protrusion and bulging were present in 96, 70, 41 and 13\% of patients, respectively [55]. These IR classifications provide a more detailed reference. The probability of SLDH regression should be considered in clinical practice according to the guidelines of the North American Spine Society [48], and we provided an extensive summary of estimated IRs as evidence. Together with existing evidence, our research shows that the regression of SLDH should be fully considered by clinical decision makers. For patients without absolute indications for surgery, the regression of SLDH can be considered very likely, and surgery may be avoided for most patients. As some SLDH patients who were treated non-surgically did not experience regression, the effective prediction of SLDH regression should be explored in the future.

Our study revealed that the study types, LDH levels and regression measurements contributed to the heterogeneity. The increase in the risk of selection bias in the three study types (RCTs, prospective studies and retrospective studies $[56,57])$ was consistent with the increase in the pooled IR of the three types of studies, explaining the heterogeneity observed among different study types. The pooled IR of studies that included only 
single-level SLDH patients was higher than that of those including both single- and multiple-level SLDH patients. Because there are usually more herniated disc tissues in single-level SLDH than in multiple-level SLDH, which induces a more robust inflammatory response, and the most likely mechanism underlying regression is an inflammatory response directed against the herniated disc tissues [58, 59], patients with single-level SLDH are more likely to experience regression than patients with multiple-level SLDH. We also found that studies that included quantitative measurements tended to report higher IRs for SLDH than studies that qualitatively measured LDH. The quantitative methods used in these included studies included 3D volume measurements and cross-sectional area measurements, while the qualitative methods used were visual estimations. Quantitative measurements were performed in millimetres or centimetres, and in some studies, they were accurate to one decimal place. In general, quantitative measurements are better for detecting small dimensional changes than visual assessments. In addition, intervertebral discs are threedimensional irregularly shaped tissues, making it difficult to capture small changes in their volume on planar images using visual estimation. Quantitative measurements made it easier to record slight changes in the size of the discs on sagittal and cross-sectional views or changes in volume that are rarely detected by visual inspection due to the occurrence of slight changes in multiple directions. Both imaging methods have obvious defects that may cause inaccuracies. For quantitative measurements, it was impossible for the follow-up images to use the exact same slices that were initially scanned [60,61]. For qualitative measurements, unclear borders and the three-dimensional characteristics of LDH made the judgement of regression inaccurate, especially for visual estimations. In the future, a more standardized and reliable method for determining the occurrence of SLDH regression needs to be established. Other factors, such as age, symptom duration, type of non-surgical treatment and follow-up time, may play a role in heterogeneity, these factors were documented in the included studies, but sufficient information was not available for determining whether these factors contributed to the heterogeneity.

Our study has limitations. We included studies in the meta-analysis without limiting the criteria or measurements for regression to ensure the robustness of IR synthesis, which inevitably led to the inclusion of sources of heterogeneity. Presently, there is no clear definition of the time frame for SLDH regression. The follow-up period of some of the included studies may not have been appropriate or long enough to observe the presence of SLDH regression, making the reported IR lower than the actual IR.

\section{Conclusions}

Our meta-analysis results supplement the guidelines of the North American Spine Society on the IR [48]. We revealed an overall IR of $63 \%$ among patients with SLDH who were treated non-surgically, thus providing clinical decision makers with quantitative evidence of IR. The probability of regression after the non-surgical treatment of SLDH should be fully considered before making decisions regarding surgery. Based on our systematic review, we suggest a follow-up timeline that consists of the time points 4 and 10.5 months after onset when deciding whether to perform surgery for SLDH. Surgery can be considered for patients with severe symptoms who do not experience regression after 4 months of onset, and we highly recommend surgery for those who do not experience regression after 10.5 months of onset.

\section{Supplementary information}

Supplementary information accompanies this paper at https://doi.org/10 1186/s12891-020-03548-z.

\section{Additional file 1.}

\section{Abbreviations}

SLDH: Symptomatic lumbar disc herniation; IR: Incidence of regression; LDH: Lumbar disc herniation; RCTs: Randomized controlled trials; MINORS: Methodological Index for Non-Randomized Studies; PRIS MA: Preferred Reporting Items for Systematic Reviews and Meta-Analyses; Cls: Confidence intervals

\section{Acknowledgements \\ We thank Sawan Bopanna (Department of Gastroenterology, All India Institute of Medical Sciences, New Delhi, India) and Vineet Ahuja (Massachusetts General Hospital, Crohn's and Colitis Center, Boston, MA, USA) for helping us with the quality assessment of non-controlled studies.}

\section{Authors' contributions}

YW had full access to all of the data in the study and takes responsibility for the integrity of the data and the accuracy of the data analysis. Concept and design: YW, GD. Acquisition, analysis, or interpretation of data: all authors. Drafting of the manuscript: YW, LJ. Critical revision of the manuscript for important intellectual content: All authors. Statistical analysis: YW, GD, SL. Obtained funding: YW. Administrative, technical, or material support: All authors. Supervision: GD. The author(s) read and approved the final manuscript.

\section{Funding}

This study was funded by Sichuan Provincial Orthopedics Hospital (grant number 2017-4).

\section{Availability of data and materials \\ Not applicable.}

Ethics approval and consent to participate Not applicable.

Consent for publication

Not applicable.

Competing interests

The authors declare that they have no conflicts of interest. 


\section{Author details}

'Cervicodynia/Omalgia/Lumbago/Sciatica Department 2, Sichuan Provincial Orthopedics Hospital, 132 West First Section First Ring Road, Chengdu 610041, Sichuan Province, China. ${ }^{2}$ College Hospital, Sichuan Agricultural University-Chengdu Campus, 211 Huimin Road, Wenjiang District, Cheng Du, Sichuan Province, China.

Received: 11 February 2020 Accepted: 29 July 2020

Published online: 10 August 2020

\section{References}

1. Saal JA, Saal JS. Nonoperative treatment of herniated lumbar intervertebral disc with radiculopathy. An outcome study. Spine (Phila Pa 1976). 1989; 14(4):431-7.

2. Peul WC, van Houwelingen HC, van den Hout WB, Brand R, Eekhof JA, Tans $J$ T, et al. Surgery versus prolonged conservative treatment for sciatica. N Engl J Med. 2007;356(22):2245-56.

3. Peul WC, van den Hout WB, Brand R, Thomeer RT, Koes BW. Leiden-the Hague spine intervention prognostic study G. prolonged conservative care versus early surgery in patients with sciatica caused by lumbar disc herniation: two year results of a randomised controlled trial. BMJ. 2008; 336(7657):1355-8.

4. Weinstein JN, Lurie JD, Tosteson TD, Skinner JS, Hanscom B, Tosteson AN, et al. Surgical vs nonoperative treatment for lumbar disk herniation: the spine patient outcomes research trial (SPORT) observational cohort. JAMA. 2006;296(20):2451-9

5. Shriver MF, Xie JJ, Tye EY, Rosenbaum BP, Kshettry VR, Benzel EC, et al. Lumbar microdiscectomy complication rates: a systematic review and metaanalysis. Neurosurg Focus. 2015;39(4):E6.

6. Ramaswami R, Ghogawala Z, Weinstein JN. Management of Sciatica. N Engl J Med. 2017;376(12):1175-7.

7. Guinto FC Jr, Hashim H, Stumer M. CT demonstration of disk regression after conservative therapy. AJNR Am J Neuroradiol. 1984;5(5):632-3.

8. Hong J, Ball PA. Images In Clinical Medicine. Resolution of lumbar disk herniation without surgery. N Engl J Med. 2016;374(16):1564.

9. El Barzouhi A, Vleggeert-Lankamp CLAM, Lycklama À, Nijeholt GJ, Van Der Kallen BF, Van Den Hout WB, Jacobs WCH, et al. Magnetic resonance imaging in follow-up assessment of sciatica. N Engl J Med. 2013;368(11): 999-1007.

10. Santilli V, Beghi E, Finucci S. Chiropractic manipulation in the treatment of acute back pain and sciatica with disc protrusion: a randomized doubleblind clinical trial of active and simulated spinal manipulations. Spine J. 2006;6(2):131-7.

11. Fan $Y, Z$ Zhao P. A randomized, placebo-controlled trial of vertebral mobilization treatment on patients with acute radiculopathy caused by lumbar disc herniation. Physiotherapy (united kingdom). 2015;101:eS1714eS5.

12. Ahn SH, Park HW, Byun WM, Ahn MW, Bae JH, Jang SH, et al. Comparison of clinical outcomes and natural morphologic changes between sequestered and large central extruded disc herniations. Yonsei Med J. 2002;43(3):28390.

13. Maigne JY, Rime B, Deligne B. Computed tomographic follow-up study of forty-eight cases of nonoperatively treated lumbar intervertebral disc herniation. Spine (Phila Pa 1976). 1992;17(9):1071-4.

14. Benson RT, Tavares SP, Robertson SC, Sharp R, Marshall RW. Conservatively treated massive prolapsed discs: a 7-year follow-up. Ann R Coll Surg Engl. 2010;92(2):147-53.

15. Komori H, Okawa A, Haro H, Muneta T, Yamamoto H, Shinomiya K. Contrastenhanced magnetic resonance imaging in conservative management of lumbar disc herniation. Spine (Phila Pa 1976). 1998;23(1):67-73.

16. Modic MT, Ross JS, Obuchowski NA, Browning KH, Cianflocco AJ, Mazanec DJ. Contrast-enhanced MR imaging in acute lumbar radiculopathy: a pilot study of the natural history. Radiology. 1995;195(2):429-35.

17. Kamanli A, Karaca-Acet G, Kaya A, Koc M, Yildirim H. Conventional physical therapy with lumbar traction; clinical evaluation and magnetic resonance imaging for lumbar disc herniation. Bratisl Lek Listy. 2010;111(10):541-4.

18. Autio RA, Karppinen J, Niinimaki J, Ojala R, Kurunlahti M, Haapea M, et al. Determinants of spontaneous resorption of intervertebral disc herniations. Spine (Phila Pa 1976). 2006;31(11):1247-52.
19. Gallucci M, Bozzao A, Orlandi B, Manetta R, Brughitta G, Lupattelli L. Does postcontrast MR enhancement in lumbar disk herniation have prognostic value? J Comput Assist Tomogr. 1995;19(1):34-8.

20. Ozturk B, Gunduz OH, Ozoran K, Bostanoglu S. Effect of continuous lumbar traction on the size of herniated disc material in lumbar disc herniation. Rheumatol Int. 2006;26(7):622-6.

21. Ahn SH, Ahn MW, Byun WM. Effect of the transligamentous extension of lumbar disc herniations on their regression and the clinical outcome of sciatica. Spine (Phila Pa 1976). 2000;25(4):475-80.

22. IIkko E, Lahde $S$, Heikkinen ER. Late CT-findings in non-surgically treated lumbar disc herniations. Eur J Radiol. 1993;16(3):186-9.

23. Delauche-Cavallier MC, Budet C, Laredo JD, Debie B, Wybier M, Dorfmann H, et al. Lumbar disc herniation: computed tomography scan changes after conservative treatment of nerve root compression. Spine. 1992;17(8):927-33.

24. Buttermann GR. Lumbar disc herniation regression after successful epidural steroid injection. J Spinal Disord Tech. 2002;15(6):469-76.

25. Bozzao A, Gallucci M, Masciocchi C, Aprile I, Barile A, Passariello R. Lumbar disk herniation: MR imaging assessment of natural history in patients treated without surgery. Radiology. 1992;185(1):135-41.

26. Broetz D, Hahn U, Maschke E, Wick W, Kueker W, Weller M. Lumbar disk prolapse: response to mechanical physiotherapy in the absence of changes in magnetic resonance imaging. Report of 11 cases. NeuroRehabilitation. 2008;23(3):289-94.

27. Jensen TS, Albert HB, Soerensen JS, Manniche C, Leboeuf-Yde C. Natural course of disc morphology in patients with sciatica: an MRI study using a standardized qualitative classification system. Spine (Phila Pa 1976). 2006; 31(14):1605-12 discussion 13.

28. Henmi T, Sairyo K, Nakano S, Kanematsu Y, Kajikawa T, Katoh S, et al. Natural history of extruded lumbar intervertebral disc herniation. J Med Investig. 2002:49(1-2):40-3.

29. Takada E, Takahashi M, Shimada K. Natural history of lumbar disc hernia with radicular leg pain: spontaneous MRI changes of the herniated mass and correlation with clinical outcome. J Orthop Surg (Hong Kong). 2001; 9(1):1-7.

30. Cribb GL, Jaffray DC, Cassar-Pullicino VN. Observations on the natural history of massive lumbar disc herniation. J Bone Joint Surg (Br). 2007;89(6):782-4.

31. Ellenberg MR, Ross ML, Honet JC, Schwartz M, Chodoroff G, Enochs S. Prospective evaluation of the course of disc herniations in patients with proven radiculopathy. Arch Phys Med Rehabil. 1993;74(1):3-8.

32. Demirel A, Yorubulut M, Ergun N. Regression of lumbar disc herniation by physiotherapy. Does non-surgical spinal decompression therapy make difference? Double-blind randomized controlled trial. J Back Musculoskelet Rehabil. 2017;30(5):1015-22.

33. Hong SJ, Kim DY, Kim H, Kim S, Shin KM, Kang SS. Resorption of massive lumbar disc herniation on MRI treated with epidural steroid injection: a retrospective study of 28 cases. Pain Physician. 2016;19(6):381-8.

34. Matsubara Y, Kato F, Mimatsu K, Kajino G, Nakamura S, Nitta H. Serial changes on MRI in lumbar disc herniations treated conservatively. Neuroradiology. 1995;37(5):378-83.

35. Yukawa Y, Kato F, Matsubara Y, Kajino G, Nakamura S, Nitta H. Serial magnetic resonance imaging follow-up study of lumbar disc herniation conservatively treated for average 30 months: relation between reduction of herniation and degeneration of disc. J Spinal Disord. 1996;9(3):251-6.

36. Fagerlund MKJ, Thelander U, Friberg S. Size of lumbar disc hernias measured using computed tomography and related to sciatic symptoms. Acta Radiol. 1990;31(6):555-8.

37. Kesikburun B, Eksioglu E, Turan A, Adiguzel E, Kesikburun S, Cakci A. Spontaneous regression of extruded lumbar disc herniation: correlation with clinical outcome. Pak J Med Sci. 2019;35(4):974-80.

38. Teplick JG, Haskin ME. Spontaneous regression of herniated nucleus pulposus. AJR Am J Roentgenol. 1985;145(2):371-5.

39. Shan Z, Fan S, Xie Q, Suyou L, Liu J, Wang C, et al. Spontaneous resorption of lumbar disc herniation is less likely when modic changes are present. Spine (Phila Pa 1976). 2014;39(9):736-44.

40. Shin JS, Lee J, Kim MR, Shin BC, Lee MS, Ha IH. The long-term course of patients undergoing alternative and integrative therapy for lumbar disc herniation: 3-year results of a prospective observational study. BMJ Open. 2014;4:e005801.

41. Komori H, Shinomiya K, Nakai O, Yamaura I, Takeda S, Furuya K. The natural history of herniated nucleus pulposus with radiculopathy. Spine (Phila Pa 1976). 1996;21(2):225-9. 
42. Saal JA, Saal JS, Herzog RJ. The natural history of lumbar intervertebral disc extrusions treated nonoperatively. Spine (Phila Pa 1976). 1990;15(7):683-6.

43. Bush K, Cowan N, Katz DE, Gishen P. The natural history of sciatica associated with disc pathology. A prospective study with clinical and independent radiologic follow-up. Spine (Phila Pa 1976). 1992;17(10):120512.

44. Iwabuchi M, Murakami K, Ara F, Otani K, Kikuchi S. The predictive factors for the resorption of a lumbar disc herniation on plain MRI. Fukushima J Med Sci. 2010;56(2):91-7.

45. Yu PF, Jiang H, Liu JT, Li XC, Qian X, Han S, et al. Traditional Chinese medicine treatment for ruptured lumbar disc herniation: clinical observations in 102 cases. Orthop Surg. 2014;6(3):229-35.

46. Lee J, Shin JS, Lee YJ, Kim J, Kim MR, Koh W, et al. Long-term course and predictive factors associated with disc resorption in lumbar disc herniation patients. J Neurol Sci. 2017:381:278.

47. Jensen TS, Albert HB, Sorensen JS, Manniche C, Leboeuf-Yde C. Magnetic resonance imaging findings as predictors of clinical outcome in patients with sciatica receiving active conservative treatment. J Manip Physiol Ther. 2007:30(2):98-108.

48. Kreiner DS, Hwang SW, Easa JE, Resnick DK, Baisden JL, Bess S, et al. An evidence-based clinical guideline for the diagnosis and treatment of lumbar disc herniation with radiculopathy. Spine J. 2014;14(1):180-91.

49. Liberati A, Altman DG, Tetzlaff J, Mulrow C, Gotzsche PC, loannidis JP, et al The PRISMA statement for reporting systematic reviews and meta-analyses of studies that evaluate healthcare interventions: explanation and elaboration. BMJ. 2009;339:b2700.

50. Slim K, Nini E, Forestier D, Kwiatkowski F, Panis Y, Chipponi J. Methodological index for non-randomized studies (minors): development and validation of a new instrument. ANZ J Surg. 2003;73(9):712-6.

51. Higgins JP, Altman DG, Gotzsche PC, Juni P, Moher D, Oxman AD, et al. The Cochrane Collaboration's tool for assessing risk of bias in randomised trials. BMJ. 2011;343:d5928.

52. TJ HJPT, Chandler J, Cumpston M, Li T, Page MJ, Welch VA. Cochrane handbook for systematic reviews of interventions version 6.0 (updated July 2019). Cochrane. :2019 Available from www.training.cochrane.org/ handbook.

53. Team RC. R: a language and environment for statistical computing. R Foundation for statistical computing, Vienna, Austria URL https://www Rproject.org/. Accessed 26 Oct 2019.

54. Zhong M, Liu JT, Jiang H, Mo W, Yu PF, Li XC, et al. Incidence of spontaneous Resorption of lumbar disc herniation: a Meta-analysis. Pain Physician. 2017;20(1):E45-52.

55. Chiu CC, Chuang TY, Chang KH, Wu CH, Lin PW, Hsu WY. The probability of spontaneous regression of lumbar herniated disc: a systematic review. Clin Rehabil. 2015;29(2):184-95.

56. Norvell DC. Study types and bias-Don't judge a study by the abstract's conclusion alone. Evid Based Spine Care J. 2010;1 (2):7-10.

57. Petrisor BA, Keating J, Schemitsch E. Grading the evidence: levels of evidence and grades of recommendation. Injury. 2006;37(4):321-7.

58. Kato $T$, Haro H, Komori H, Shinomiya K. Sequential dynamics of inflammatory cytokine, angiogenesis inducing factor and matrix degrading enzymes during spontaneous resorption of the herniated disc. J Orthop Res. 2004;22(4):895-900.

59. Macki M, Hernandez-Hermann M, Bydon M, Gokaslan A, McGovern K, Bydon A. Spontaneous regression of sequestrated lumbar disc herniations: literature review. Clin Neurol Neurosurg. 2014;120:136-41.

60. Seo JY, Roh YH, Kim YH, Ha KY. Three-dimensional analysis of volumetric changes in herniated discs of the lumbar spine: does spontaneous resorption of herniated discs always occur? Eur Spine J. 2016;25(5):1393402.

61. Kawaji Y, Uchiyama S, Yagi E. Three-dimensional evaluation of lumbar disc hernia and prediction of absorption by enhanced MRI. J Orthop Sci. 2001; 6(6):498-502.

\section{Publisher's Note}

Springer Nature remains neutral with regard to jurisdictional claims in published maps and institutional affiliations.

Ready to submit your research? Choose BMC and benefit from:

- fast, convenient online submission

- thorough peer review by experienced researchers in your field

- rapid publication on acceptance

- support for research data, including large and complex data types

- gold Open Access which fosters wider collaboration and increased citations

- maximum visibility for your research: over $100 \mathrm{M}$ website views per year

At BMC, research is always in progress.

Learn more biomedcentral.com/submissions 